\title{
Evaluation of nutritional quality of biscuits and sweet snacks sold on the Italian market: the Food Labelling of Italian Products (FLIP) study
}

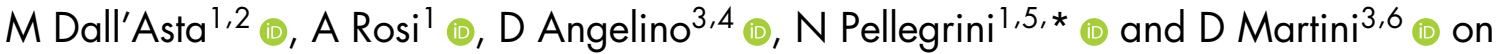
behalf of the Italian Society of Human Nutrition (SINU) Young Working Group

'Department of Food and Drug, Human Nutrition Unit, University of Parma, Parma, Italy: ${ }^{2}$ Department of Animal Science, Food and Nutrition, Università Cattolica del Sacro Cuore, Piacenza, Italy: ${ }^{3}$ Department of Veterinary Science, Human Nutrition Unit, University of Parma, Parma, Italy: ${ }^{4}$ Faculty of Bioscience and Technology for Food, Agriculture and Environment, University of Teramo, Teramo, Italy: ${ }^{5}$ Department of Agricultural, Food, Environmental and Animal Sciences, University of Udine, Udine, Italy: ${ }^{6}$ Department of Food, Environmental and Nutritional Sciences (DeFENS), Università degli Studi di Milano, Milan, Italy
\end{abstract}

Submitted 28 October 2019: Final revision received 21 February 2020: Accepted 6 March 2020: First published online 8 July 2020

\begin{abstract}
Objective: The present study aimed at surveying the nutritional quality of prepacked biscuits and sweet snacks sold on the Italian market, and at identifying whether the product type and other information reported on the pack could discriminate the overall quality of products analysed.

Design: Data on energy, nutrient and salt content of the products from two different categories of prepacked sweet cereal products (i.e. biscuits and sweet snacks) were collected from thirteen retailers present on the Italian market. Based on the product type, nutrition and health claim (NHC) and gluten-free (GF) declaration, a comparison of nutrient profile within each category was performed.

Setting: This work is part of the Food Labelling of Italian Products (FLIP) study that aims at systematically investigating the overall quality of the prepacked foods sold on the Italian market.

Results: A total of 1290 products were analysed (63\% biscuits and 37\% sweet snacks). After comparing different product types within each category, a high intra-type product variability was evidenced, which was more pronounced for biscuits. Overall, NHC-carrying products seemed to have a better nutrition profile than those without claims, except for salt content. Conversely, a comparison between GF and gluten-containing products did not show consistent results within the two categories analysed.

Conclusions: Due to the high intra-type variability within each category, the different characteristics and regulated information reported on the pack do not seem to be a clear marker of the overall nutritional quality of biscuits and snacks.
\end{abstract}

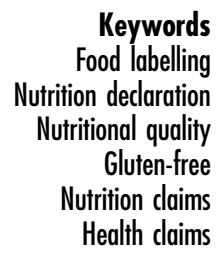

Food labelling represents one of the principal tools for food companies to communicate with consumers at the time of purchase. Over the years, messages reported on the pack drastically increased with the aim to inform consumers

†SINU Young Working Group: Daniele Nucci - Veneto Institute of Oncology IOV-IRCCS, Padova, Italy; Gaetana Paolella - Department of Chemistry and Biology A. Zambelli, University of Salerno, Fisciano, Italy; Emilia Ruggiero, Veronica Pignone - Department of Epidemiology and Prevention, IRCCS Neuromed, Pozzilli, Italy; Stefania Moccia, Carmela Spagnuolo, Marika Dello Russo - Institute of Food Sciences, National Research Council, Avellino, Italy. about the product characteristics and nutritional qualities. This phenomenon has created a complex and crowded label environment in which a wide number of claims coexist. Regarding facts made on foods, the European Commission specifically regulates information that must be provided to consumers, such as the list of ingredients and the nutrition declaration (Regulation (EU) n. 1169/ $2011)^{(1)}$. Moreover, the European Commission strictly supervises other declarations, such as nutrition and health claims (NHC), which can be provided on the pack on a 
voluntary basis (Regulation (CE) n. 1924/2006) and which state about beneficial nutritional properties (e.g. 'rich in fibre') or relationships between food and health (e.g. 'contributes to the maintenance of normal blood cholesterol levels' $)^{(2)}$. In this context, NHC could play a key role in enabling consumers to make healthier food choices ${ }^{(3,4)}$. However, it has been reported that NHC may not directly predict the overall nutritional quality of products ${ }^{(5)}$ or paradoxically overestimates their healthiness ${ }^{(6,7)}$ and subsequently increases the consumption of products bearing claims ${ }^{(8-10)}$. Likewise, products carrying gluten-free (GF) declaration (as defined by the Regulation (EU) n. 828/2014) ${ }^{(11)}$ are gaining interest from non-coeliac consumers due to the perception of a better nutrition profile than the gluten-containing (GC) counterpart, although evidence describes an equivalent or even lower quality of GF than GC products ${ }^{(12,13)}$. As a result, consumers' perception of product quality and, in turn, their intention to buy is affected by the sum of these factors ${ }^{(14)}$. Therefore, the messages claimed on the pack may have a dual and opposite role: (1) to become a platform for implementing specific health-related policies for informing and educating consumers and, in turn, influencing industry practices and (2) to generate a misleading scenario, becoming an easy tool for marketing.

Certainly, the nutritional quality of food products is a result of several factors, which may be only partially described by NHC as well as other messages on specific characteristics, as this information generally focuses on one or more food components and not on the overall quality of the product. Previous reports focused on the quality of products sold in different markets worldwide; however, only few of them specifically compared the nutritional quality based on specific characteristics such as the presence of $\mathrm{NHC}^{(15)}$ or GF declaration ${ }^{(12,13,16)}$. Despite this limited and preliminary evidence, the appropriateness of using specific characteristics on the food pack for describing the nutritional quality of food products needs to be fully investigated.

Cereal-based products represent one of the most consumed foods, not only in Italy ${ }^{(17)}$ but also worldwide ${ }^{(18)}$. Nutrition information (e.g. NHC, GF declaration) may have a large application on this food group, due to its nutritional composition $^{(19)}$. So far, the nutritional quality of cereal based-food products sold on the Italian market, based on the characteristics of products (e.g. type) or declarations (e.g. GF or presence of NHC), has not yet been comprehensively and systematically described.

Therefore, the aims of the present study were: (i) to investigate the nutritional quality of two categories of sweet cereal-based products (biscuits and sweet snacks), collecting their nutrition declarations from packaging, and (ii) to compare their energy, nutrient and salt contents based on different characteristics (type of product, presence/ absence of NHC, GF declaration). This work is part of the Food Labelling of Italian Products (FLIP) study that aims at systematically investigating the overall quality of the prepacked foods sold on the Italian market ${ }^{(20-22)}$.

\section{Materials and methods}

\section{Food product selection}

Foods from two categories (i.e. biscuits and sweet snacks) were analysed. Products were selected from the home-shopping website of thirteen retailers present on the Italian market (Auchan, Bennet, Carrefour, Conad, Coop Italia, Crai, Despar, Esselunga, Il Gigante, Iper, Pam Panorama, Selex, Sidis).

Online search for food products was performed from July 2018 until December 2018. All the items present in the two categories of interest in each online shop were considered eligible for data extraction.

The exclusion criteria were: (i) not prepacked foods, (ii) incomplete images of all the sides of the pack, (iii) unclear images of nutrition declaration and/or list of ingredients and (iv) products marked 'currently unavailable' on all the online stores.

\section{Data extraction}

Images of all the sides of each pack were collected for all included products. For each food item, the following specifically regulated (mandatory) quali-quantitative information was retrieved: company name, brand name, descriptive name, energy (kcal/100 g), total fat (g/100 g), saturates $(\mathrm{g} / 100 \mathrm{~g})$, carbohydrate $(\mathrm{g} / 100 \mathrm{~g})$, sugars $(\mathrm{g} / 100 \mathrm{~g})$, protein (g/100 g) and salt (g/100 g). Moreover, the following voluntary declarations were collected: NHC (presence or absence of at least one nutrition or health claim) and GF declaration (either 'specifically formulated for coeliacs' or 'containing gluten').

The precision of extracted data was double-checked by two researchers, and inaccuracies were solved through secondary extractions.

A dataset was created with all the collected data, grouping products into the two categories of interest: biscuits and sweet snacks. Items were further sub-grouped for specific comparisons, considering (i) the descriptive name reported, (ii) the presence/absence of GF declaration and (iii) the presence/absence of NHC declaration. Based on the descriptive name, biscuits were divided in six types (tea cookies, short-bread biscuits, cream-filled wafer, covered and/or sandwich cookies, Italian traditional biscuits (e.g. cantucci and amaretti) and other biscuits); similarly, sweet snacks were grouped in six types (cream-filled sponge cake, plain or cream/jam-filled croissant or pain au chocolat, yogurt plumcake and muffin, sponge cake, cream/jamfilled shortbread cake, cream-filled and/or covered chilled snack). 


\section{Statistical analysis}

Statistical analysis was carried out using the Statistical Package for Social Sciences software (IBM SPSS Statistics, version 25.0, IBM Corp.) and performed at $P<0.05$ of significance level. The normality of data distribution was rejected through the Kolmogorov-Smirnov test, and variables were expressed as median (IQR).

Data regarding energy, nutrients and salt content per $100 \mathrm{~g}$ of a product for each product category were analysed to explore differences using the Kruskal-Wallis nonparametric one-way ANOVA for independent samples with multiple pairwise comparisons (for differences among types and GF declaration categories) and using the MannWhitney non-parametric test for two independent samples (for differences between nutrition claim categories and health claim categories). In addition, a principal component analysis (PCA) with varimax rotation was performed for all products and by each product category considering energy, nutrients and salt content per $100 \mathrm{~g}$ of a product to better describe the inter-product nutrition variability.

\section{Results}

A total of 1483 sweet cereal-based products were identified during the online search performed from July 2018 until December 2018. These products included 961 items for biscuits and 522 for sweet snacks categories. After applying the exclusion criteria, a total of 1290 products were eligible for data extraction, of which $63 \%(n$ 814) were biscuits and $37 \%$ ( $n$ 476) were sweet snacks.

Values of energy, nutrients and salt content (g/100 g) for each category, with statistical comparison by category, are presented in Tables 1 and 2. Energy, nutrients and salt contents showed a high variability among the considered product categories. The total median energy was 471 (449-489) and $408(387-427) \mathrm{kcal} / 100 \mathrm{~g}$ for biscuits and sweet snacks, respectively. Total carbohydrates were the most representative macronutrient in biscuits ( $57 \%$ of energy) and sweet snacks (53\% of energy), with sugars accounting for $36 \%$ of the total carbohydrates in biscuits and $53 \%$ in sweet snacks. Total fat contributed to the energy content as follows: $41 \%$ for sweet snacks and $37 \%$ for biscuits, with saturates covering $37 \%$ of total fat for sweet snacks and $30 \%$ for biscuits.

Inter-product variability was described by three principal components (PC), which explained $73 \%$ of variation among products (Fig. 1). PC1 accounted for 33\% of total variability and was positively loaded by energy, total fat and saturates. PC2 explained $21 \%$ of variability and had positive loadings from protein and salt and a negative loading from sugars. The remaining $19 \%$ of variability was explained by PC3, which was positively loaded by carbohydrates. The two product categories presented an overlap due to a high variability in terms of nutrition profile among products within the same category. However, product categories were grouped based on their carbohydrate content (positive scores for PC3, Fig. 1(c) and (d)) as well as on their energy, total fat and saturate contents (positive scores for PC1, Fig. 1(a) and (b)), all being higher in biscuits than in sweet snacks.

\section{Biscuits}

The energy content of the biscuit category significantly varied across the types of products $(P<0 \cdot 001)$, from a median of $438 \mathrm{kcal} / 100 \mathrm{~g}$ (384-489) for Italian traditional biscuits to $520 \mathrm{kcal} / 100 \mathrm{~g}(511-530)$ for cream-filled wafer and $520 \mathrm{kcal} / 100 \mathrm{~g}$ (479-545) for other biscuits (Table 1). Accordingly, the cream-filled wafer type showed the highest content of total fat and saturates and the lowest of carbohydrates. Items specifically formulated for coeliacs had lower total energy than GC products $(P<0.001)$ as a consequence of lower total fat content $(P=0.019)$ although higher in total carbohydrates $(P<0 \cdot 001)$. For biscuits carrying a nutrition or health claim, lower contents of total energy $(P<0.001$ and $P<0.001$, respectively), total fat $(P<0.001$ and $P=0.002$, respectively), saturates ( $P<0.001$ for both), carbohydrates $(P=0.021$ only for health claim) and sugars $(P<0.001$ and $P<0.001$, respectively) were identified, while protein was higher $(P<0.001$ and $P=0.002$, respectively) than the non-claiming counterparts. Finally, the salt content in products with at least one nutrition claim was significantly higher compared to products without claims $(P<0.001)$.

A high inter-product variability was observed among the biscuit types (Fig. 2(a) and (b)), estimated at $67 \%$ (45 and $22 \%$, respectively by PC1 and PC2). Energy, total fat and saturates were the main loadings positively associated with PC1, while the carbohydrate content was negatively associated with PC1. PC2 had a positive component loading from sugars and a negative load from protein and salt (Fig. 2(a)). As reported in Fig. 2(b), the score plot shows a good separation among some biscuit types. In particular, the cream-filled wafers grouped well, even if partially overlapping with other biscuit types. These products showed the highest score for PC1, related to high energy, total fat and saturates. On the contrary, tea cookies and short-bread biscuits were very similar, presenting a comparable quantity of protein and a low sugar content (i.e. most of them presented negative PC2 scores), and wide differences in energy and total fat. Other biscuit types were scarcely represented and showed a high inter-product variability.

\section{Sweet snacks}

Although no differences were identified among the sweet snack types for energy content, they varied from a median of $403 \mathrm{kcal} / 100 \mathrm{~g}$ (371-428) for cream-filled sponge cake and $403 \mathrm{kcal} / 100 \mathrm{~g}$ (383-428) for yogurt plumcake and muffin, to a median of $439 \mathrm{kcal} / 100 \mathrm{~g}$ (422-446) for cream-filled and/or covered chilled snack (Table 2). On the contrary, differences among sweet snack types were found for total fat $(P<0.001)$, saturates $(P<0.001)$, carbohydrates 
Table 1 Energy, macronutrients and salt contents in the biscuit category*

\begin{tabular}{|c|c|c|c|c|c|c|c|c|c|c|c|c|c|c|c|c|}
\hline \multirow{2}{*}{\multicolumn{2}{|c|}{ Items }} & \multirow[b]{2}{*}{$\begin{array}{l}\text { Number } \\
\text { of items }\end{array}$} & \multicolumn{2}{|c|}{ Energy $\left(\mathrm{kcal}^{\dagger} / 100 \mathrm{~g}\right)$} & \multicolumn{2}{|c|}{ Total fat $(\mathrm{g} / 100 \mathrm{~g})$} & \multicolumn{2}{|c|}{ Saturates $(\mathrm{g} / 100 \mathrm{~g})$} & \multicolumn{2}{|c|}{ Carbohydrate (g/100 g) } & \multicolumn{2}{|c|}{ Sugars $(\mathrm{g} / 100 \mathrm{~g})$} & \multicolumn{2}{|c|}{ Protein $(\mathrm{g} / 100 \mathrm{~g})$} & \multicolumn{2}{|c|}{ Salt (g/100 g) } \\
\hline & & & Median & $\begin{array}{l}25 \text { th, } 75 \text { th } \\
\text { percentile }\end{array}$ & Median & $\begin{array}{l}25 \text { th, } 75 \text { th } \\
\text { percentile }\end{array}$ & Median & $\begin{array}{l}\text { 25th, } 75 \text { th } \\
\text { percentile }\end{array}$ & Median & $\begin{array}{l}\text { 25th, } 75 \text { th } \\
\text { percentile }\end{array}$ & Median & $\begin{array}{l}\text { 25th, } 75 \text { th } \\
\text { percentile }\end{array}$ & Median & $\begin{array}{l}\text { 25th, } 75 \text { th } \\
\text { percentile }\end{array}$ & Median & $\begin{array}{l}\text { 25th, 75th } \\
\text { percentile }\end{array}$ \\
\hline Category & Biscuits & 814 & 471 & 449,489 & $18 \cdot 8$ & $15 \cdot 9,22 \cdot 0$ & 5.7 & $2 \cdot 4,10 \cdot 5$ & $66 \cdot 4$ & $62 \cdot 0,70$ & $24 \cdot 0$ & $21 \cdot 0,28 \cdot 3$ & $7 \cdot 3$ & $6 \cdot 5,8 \cdot 1$ & 0.5 & $0.4,0.8$ \\
\hline \multirow[t]{6}{*}{ Type } & Tea cookies & 253 & 456 & $438,472^{\mathrm{d}}$ & $16 \cdot 3$ & $13 \cdot 0,19 \cdot 5^{\mathrm{d}}$ & 4.2 & $2 \cdot 0,8 \cdot 1^{\mathrm{c}}$ & 67.7 & $63 \cdot 1,72 \cdot 7^{\mathrm{a}}$ & 23.0 & $19 \cdot 1,26 \cdot 6^{b}$ & 7.8 & $6 \cdot 9,8 \cdot 5^{\mathrm{a}}$ & 0.6 & $0.4,0.8^{\mathrm{a}}$ \\
\hline & $\begin{array}{l}\text { Short-bread } \\
\text { biscuits }\end{array}$ & 357 & 470 & $454,480^{c}$ & $18 \cdot 2$ & $16 \cdot 0,20 \cdot 0^{c}$ & 4.4 & $2 \cdot 3,7 \cdot 1^{\mathrm{c}}$ & 67.4 & $64.5,70 \cdot 0^{\mathrm{a}}$ & 22.6 & $20 \cdot 0,25 \cdot 0^{\mathrm{b}}$ & 7.3 & $6 \cdot 7,7.9^{b}$ & 0.6 & $0.5,0.8^{\mathrm{a}}$ \\
\hline & $\begin{array}{l}\text { Cream-filled } \\
\text { wafer }\end{array}$ & 76 & 520 & $511,530^{\mathrm{a}}$ & $27 \cdot 0$ & $26 \cdot 0,30 \cdot 0^{a}$ & $22 \cdot 0$ & $20 \cdot 0,23 \cdot 3^{a}$ & 59.0 & $57 \cdot 9,62 \cdot 0^{c}$ & $28 \cdot 0$ & $26 \cdot 8,34 \cdot 0^{a}$ & 6.6 & $5 \cdot 9,7 \cdot 8^{\mathrm{bc}}$ & 0.3 & $0 \cdot 3,0 \cdot 4^{c}$ \\
\hline & $\begin{array}{l}\text { Covered and/or } \\
\text { sandwich } \\
\text { cookies }\end{array}$ & 78 & 495 & $476,512^{b}$ & $23 \cdot 0$ & $20 \cdot 0,26 \cdot 2^{b}$ & $10 \cdot 8$ & $7 \cdot 8,14 \cdot 1^{b}$ & $64 \cdot 3$ & $60 \cdot 3,68 \cdot 0^{b}$ & 36.0 & $29 \cdot 0,39 \cdot 0^{a}$ & $6 \cdot 2$ & $5 \cdot 3,6 \cdot 8^{\mathrm{c}}$ & 0.5 & $0.3,0.7^{b}$ \\
\hline & $\begin{array}{l}\text { Italian traditional } \\
\text { biscuits }\end{array}$ & 28 & 438 & $384,489^{\mathrm{cd}}$ & $11 \cdot 2$ & $3.8,22 \cdot 5^{\mathrm{cd}}$ & 1.9 & $0.9,11 \cdot 0^{c}$ & 76.5 & $63 \cdot 5,78 \cdot 0^{\mathrm{a}}$ & $42 \cdot 0$ & $36 \cdot 5,48 \cdot 1^{a}$ & $7 \cdot 2$ & $6 \cdot 7,8 \cdot 1^{\mathrm{ab}}$ & 0.2 & $0.1,0.3^{c}$ \\
\hline & Other biscuits & 22 & 520 & $479,545^{\mathrm{ab}}$ & $27 \cdot 3$ & $22 \cdot 0,32 \cdot 0^{\mathrm{ab}}$ & $13 \cdot 3$ & $11 \cdot 0,16 \cdot 0^{\mathrm{ab}}$ & 59.6 & $55 \cdot 0,63 \cdot 0^{c}$ & 28.8 & $25 \cdot 3,37 \cdot 0^{\mathrm{a}}$ & 6.5 & $6 \cdot 0,8 \cdot 2^{\mathrm{abc}}$ & 0.4 & $0.2,0.8^{a b}$ \\
\hline \multirow{2}{*}{$\begin{array}{l}\text { Gluten } \\
\text { content }\end{array}$} & Containing gluten & 760 & 472 & $450,489^{a}$ & $19 \cdot 0$ & $16 \cdot 0,22 \cdot 0^{\mathrm{a}}$ & $5 \cdot 7$ & $2 \cdot 4,11 \cdot 0$ & 66.0 & $62 \cdot 0,70 \cdot 0^{\mathrm{b}}$ & 24.0 & $21 \cdot 0,28 \cdot 0$ & $7 \cdot 4$ & $6 \cdot 6,8 \cdot 1^{\mathrm{a}}$ & 0.6 & $0.4,0.8^{a}$ \\
\hline & Gluten-free & 54 & 460 & $434,474^{b}$ & $17 \cdot 1$ & $15 \cdot 0,21 \cdot 0^{\mathrm{b}}$ & 6.0 & $2 \cdot 9,4 \cdot 0$ & $72 \cdot 0$ & $64 \cdot 2,74 \cdot 0^{\mathrm{a}}$ & $24 \cdot 2$ & $19 \cdot 0,31 \cdot 3$ & 4.4 & $3.5,5.9^{b}$ & 0.5 & $0.3,0.7^{b}$ \\
\hline Nutrition & No & 582 & 477 & $457,500^{\mathrm{a}}$ & 19.3 & $16 \cdot 0,24 \cdot 0^{\mathrm{a}}$ & 7.3 & $3 \cdot 4,12 \cdot 9^{a}$ & $66 \cdot 1$ & $62 \cdot 0,70 \cdot 0$ & 25.5 & $22 \cdot 2,31 \cdot 0^{\mathrm{a}}$ & 7.2 & $6 \cdot 3,7 \cdot 9^{b}$ & 0.5 & $0.3,0.7^{b}$ \\
\hline & Yes & 232 & 456 & $436,470^{b}$ & $17 \cdot 0$ & $14 \cdot 1,19 \cdot 3^{\mathrm{b}}$ & $2 \cdot 8$ & $1 \cdot 9,5 \cdot 9^{b}$ & 66.9 & $62 \cdot 7,70 \cdot 2$ & $21 \cdot 2$ & $17 \cdot 4,24 \cdot 8^{b}$ & 7.6 & $6 \cdot 9,8 \cdot 4^{\mathrm{a}}$ & 0.6 & $0.5,0.8^{a}$ \\
\hline \multirow[t]{2}{*}{ Health claim } & No & 778 & 472 & $450,489^{\mathrm{a}}$ & $19 \cdot 0$ & $16 \cdot 0,22 \cdot 0^{a}$ & 5.9 & $2 \cdot 6,11 \cdot 0^{\mathrm{a}}$ & 66.6 & $62 \cdot 0,70 \cdot 1^{a}$ & 24.0 & $21 \cdot 3,29 \cdot 0^{\mathrm{a}}$ & 7.3 & $6.5,8.0^{\mathrm{b}}$ & 0.5 & $0.3,0.8$ \\
\hline & Yes & 36 & 448 & $428,463^{b}$ & $17 \cdot 1$ & $14 \cdot 0,19 \cdot 2^{b}$ & 2.6 & $2 \cdot 0,4 \cdot 9^{\mathrm{b}}$ & 63.2 & $61 \cdot 4,68 \cdot 0^{\mathrm{b}}$ & 19.0 & $17 \cdot 3,22 \cdot 9^{b}$ & 7.9 & $7 \cdot 4,9 \cdot 0^{\mathrm{a}}$ & 0.6 & $0.5,0.8$ \\
\hline
\end{tabular}

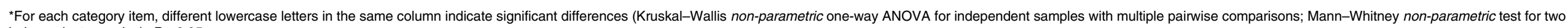
independent samples), $P<0.05$.

†To convert kcal to kJ, multiply energy values by $4 \cdot 184$.

Table 2 Energy, macronutrients and salt contents in the sweet snack category ${ }^{*}$

\begin{tabular}{|c|c|c|c|c|c|c|c|c|c|c|c|c|c|c|c|c|}
\hline \multirow{2}{*}{\multicolumn{2}{|c|}{ Items }} & \multirow[b]{2}{*}{$\begin{array}{l}\text { Number } \\
\text { of items }\end{array}$} & \multicolumn{2}{|c|}{ Energy $\left(\mathrm{kcal}^{\dagger} / 100 \mathrm{~g}\right)$} & \multicolumn{2}{|c|}{ Total Fat (g/100 g) } & \multicolumn{2}{|c|}{ Saturates (g/100 g) } & \multicolumn{2}{|c|}{ Carbohydrate (g/100 g) } & \multicolumn{2}{|c|}{ Sugars $(\mathrm{g} / 100 \mathrm{~g})$} & \multicolumn{2}{|c|}{ Protein $(\mathrm{g} / 100 \mathrm{~g})$} & \multicolumn{2}{|c|}{ Salt (g/100 g) } \\
\hline & & & Median & $\begin{array}{l}\text { 25th, 75th } \\
\text { percentile }\end{array}$ & Median & $\begin{array}{l}\text { 25th, } 75 \text { th } \\
\text { percentile }\end{array}$ & Median & $\begin{array}{l}\text { 25th, } 75 \text { th } \\
\text { percentile }\end{array}$ & Median & $\begin{array}{l}\text { 25th, } 75 \text { th } \\
\text { percentile }\end{array}$ & Median & $\begin{array}{l}\text { 25th, } 75 \text { th } \\
\text { percentile }\end{array}$ & Median & $\begin{array}{l}\text { 25th, } 75 \text { th } \\
\text { percentile }\end{array}$ & Median & $\begin{array}{l}25 \text { th, } 75 \text { th } \\
\text { percentile }\end{array}$ \\
\hline Category & Sweet snacks & 476 & 408 & 387,427 & 18.5 & $15 \cdot 1,21 \cdot 5$ & 6.8 & $3.9,9.9$ & 53.0 & $50 \cdot 0,57 \cdot 1$ & $28 \cdot 0$ & $22 \cdot 0,34 \cdot 0$ & 6.3 & $5 \cdot 5,7 \cdot 2$ & 0.5 & $0.4,0.7$ \\
\hline \multirow{5}{*}{ Type } & Cream-filled sponge cake & 51 & 403 & 371,428 & $18 \cdot 0$ & $12 \cdot 6,21 \cdot 7^{\mathrm{bc}}$ & 8.2 & $4 \cdot 8,13 \cdot 8^{\mathrm{bc}}$ & 54.2 & $51 \cdot 0,58 \cdot 0^{\mathrm{bc}}$ & 36.7 & $33 \cdot 0,38 \cdot 2^{\mathrm{a}}$ & 5.8 & $5 \cdot 5,6 \cdot 3^{\mathrm{bc}}$ & 0.4 & $0.3,0.5^{c}$ \\
\hline & $\begin{array}{l}\text { Plain or cream/jam-filled croissant or } \\
\text { pain au chocolat }\end{array}$ & 150 & 412 & 391,424 & 19.0 & $16 \cdot 1,21 \cdot 0^{\mathrm{b}}$ & 9.2 & $6 \cdot 1,11 \cdot 0^{\mathrm{ab}}$ & $51 \cdot 1$ & $49 \cdot 0,54 \cdot 2^{\mathrm{c}}$ & $21 \cdot 7$ & $16 \cdot 0,24 \cdot 0^{c}$ & 7.1 & $6 \cdot 0,6,8^{a}$ & 0.6 & $0.5,0.7^{\mathrm{ab}}$ \\
\hline & Yogurt plumcake and muffin & 149 & 403 & 383,428 & $19 \cdot 0$ & $15 \cdot 3,21 \cdot 0^{\mathrm{bc}}$ & 3.7 & $2 \cdot 6,6.0^{\mathrm{d}}$ & 52 & $50 \cdot 0,55 \cdot 0^{c}$ & 30.0 & $25 \cdot 8,34.0^{\mathrm{b}}$ & $6 \cdot 2$ & $5 \cdot 3,7 \cdot 0^{\mathrm{b}}$ & 0.6 & $0.5,0.8^{a}$ \\
\hline & Sponge cake & 89 & 413 & 389,432 & $16 \cdot 1$ & $13 \cdot 8,23 \cdot 0^{\mathrm{bc}}$ & 7.4 & $5 \cdot 8,9 \cdot 8^{\mathrm{bc}}$ & 57.0 & $53 \cdot 0,63 \cdot 7^{b}$ & 31.0 & $27 \cdot 5,34.9^{b}$ & 5.5 & $5 \cdot 0,6 \cdot 2^{\mathrm{c}}$ & 0.4 & $0.4,0.5^{\mathrm{c}}$ \\
\hline & $\begin{array}{l}\text { Cream-filled and/or covered chilled } \\
\text { snack }\end{array}$ & 6 & 439 & 422,446 & $28 \cdot 1$ & $25 \cdot 0,28 \cdot 3^{\mathrm{a}}$ & $17 \cdot 4$ & $15 \cdot 7,18 \cdot 1^{\mathrm{a}}$ & 39.8 & $34 \cdot 8,41 \cdot 5^{\mathrm{d}}$ & 33.3 & $29 \cdot 5,34 \cdot 5^{\mathrm{ab}}$ & $5 \cdot 7$ & $5 \cdot 3,7 \cdot 0^{\mathrm{abc}}$ & 0.2 & $0.2,0.6^{\mathrm{bc}}$ \\
\hline \multirow{6}{*}{$\begin{array}{l}\text { Gluten } \\
\text { content } \\
\text { Nutrition } \\
\text { claim } \\
\text { Health claim }\end{array}$} & Containing gluten & 444 & 408 & $387,425^{\mathrm{b}}$ & $18 \cdot 0$ & $15 \cdot 0,21 \cdot 0^{\mathrm{b}}$ & $7 \cdot 0$ & $4 \cdot 1,10 \cdot 0$ & $53 \cdot 0$ & $50 \cdot 0,57 \cdot 4$ & $28 \cdot 1$ & $22 \cdot 0,34 \cdot 0$ & 6.4 & $5 \cdot 5$ & 0.5 & $0.4,0.7$ \\
\hline & Gluten-free & 32 & 432 & $398,445^{a}$ & $21 \cdot 2$ & $17 \cdot 6,22 \cdot 0^{a}$ & 4.7 & $3 \cdot 3,8 \cdot 0$ & 53.0 & $50 \cdot 0,56 \cdot 5$ & $27 \cdot 1$ & $24.0,31.5$ & 5.0 & $3 \cdot 9,5 \cdot 8^{\mathrm{b}}$ & 0.6 & $0.4,0.7$ \\
\hline & No & 408 & 412 & $390,429^{a}$ & 18.9 & $15 \cdot 5,22 \cdot 0^{\mathrm{a}}$ & 7.4 & $4 \cdot 6,10 \cdot 0^{\mathrm{a}}$ & 53.0 & $50 \cdot 3,57 \cdot 7$ & 28.6 & $22 \cdot 1,34 \cdot 0^{\mathrm{a}}$ & $6 \cdot 2$ & $5 \cdot 5,7 \cdot 0^{\mathrm{b}}$ & 0.5 & $0.4,0.7^{b}$ \\
\hline & Yes & 68 & 387 & $368,405^{b}$ & 17.0 & $12 \cdot 4,20 \cdot 6^{\mathrm{b}}$ & 3.8 & $2 \cdot 6,6 \cdot 4^{\mathrm{b}}$ & 52.0 & $49,56 \cdot 8$ & $26 \cdot 2$ & $13 \cdot 3,33 \cdot 2^{\mathrm{b}}$ & 6.9 & $5 \cdot 7,7 \cdot 8^{\mathrm{a}}$ & 0.6 & $0.5,0.8^{\mathrm{a}}$ \\
\hline & No & 472 & 408 & 388,427 & 18.6 & $15 \cdot 2,21 \cdot 6$ & 6.8 & $4,9 \cdot 9 \cdot 0^{\mathrm{a}}$ & $53 \cdot 0$ & $50 \cdot 0,57 \cdot 1$ & 28.0 & $22 \cdot 0,34 \cdot 0$ & $6 \cdot 2$ & $5 \cdot 5,7 \cdot 2$ & 0.5 & $0.4,0.7$ \\
\hline & Yes & 4 & 388 & 349,408 & 14.6 & $11 \cdot 0,18 \cdot 0$ & 2.4 & $1.9,3.0^{\mathrm{b}}$ & 54.1 & $51 \cdot 5,58 \cdot 8$ & 30.0 & $15 \cdot 5,34 \cdot 4$ & 7.4 & $5 \cdot 4,7.7$ & 0.4 & $0.3,0.5$ \\
\hline
\end{tabular}

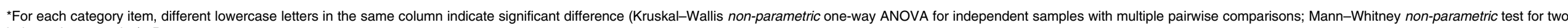
independent samples), $P<0.05$.

†To convert kcal to $\mathrm{kJ}$, multiply energy values by 4.184 . 
Nutritional quality of biscuits and snacks

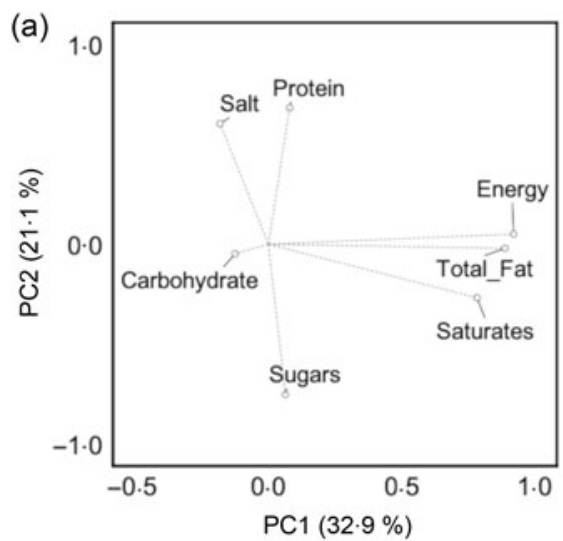

(c)

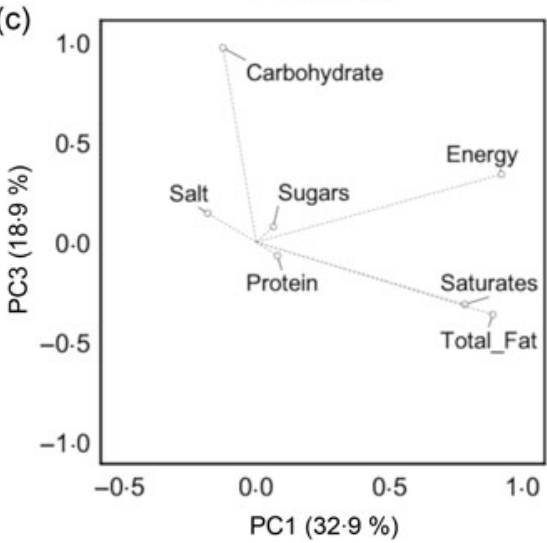

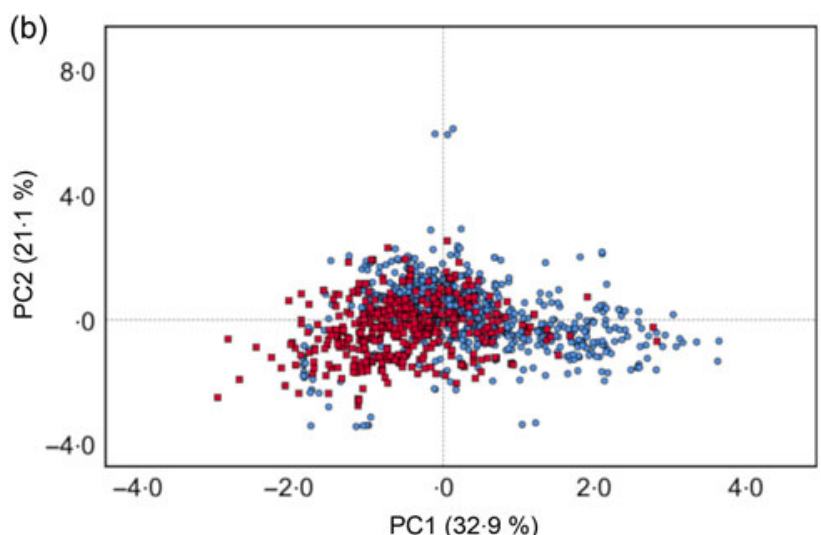

(d)

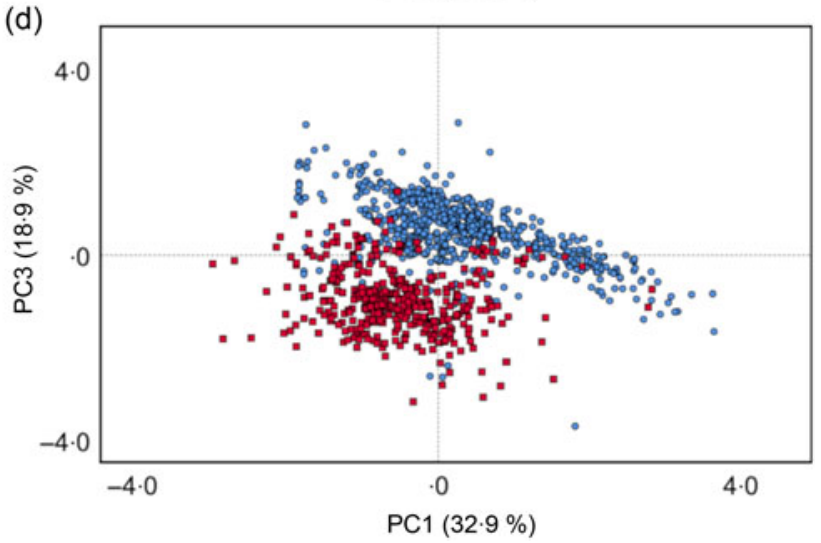

Fig. 1 (colour online) Principal component (PC) analysis describing the intra-category variability of products based on their nutrient composition (energy $(\mathrm{kcal} / 100 \mathrm{~g})$, total fat $(\mathrm{g} / 100 \mathrm{~g})$, saturates $(\mathrm{g} / 100 \mathrm{~g})$, carbohydrate $(\mathrm{g} / 100 \mathrm{~g})$, sugars $(\mathrm{g} / 100 \mathrm{~g})$, protein $(\mathrm{g} / 100 \mathrm{~g})$ and salt $(\mathrm{g} / 100 \mathrm{~g})$ ). Loading plots of PC1 v. PC2 (a) and PC1 v. PC3 (c); score plots of the nutrient composition of each product analysed within each category (biscuits and sweet snacks) from PC1 and PC2 (b) and PC1 and PC3 (d). (b, d) $\square$, sweet snacks; o, biscuits

$(P<0.001)$, sugars $(P<0 \cdot 001)$ and protein $(P<0 \cdot 001)$. The cream-filled and/or covered chilled snacks were characterised by higher total fat content and saturates and lower carbohydrates compared to other types. The yogurt plumcake and muffin type had the lowest content of saturates, while the lowest amount of sugars was found for plain or cream/jam-filled croissant or pain au chocolat. Products specifically formulated for coeliacs were higher in energy $(P=0.016)$ than the GC counterparts, due to their higher content of total fat $(P=0.009)$. Energy $(P<0.001)$, total fat and saturates $(P=0.001$ and $P<0.001$, respectively) and sugars $(P=0.002)$ were significantly lower in sweet snacks with a nutrition claim, while they had higher protein $(P=0.011)$ and salt $(P=0.004)$ contents than their counterparts. Finally, the presence of a health claim did not affect the overall nutritional quality of products, but saturates were lower in products with claims $(P=0.004) \mathrm{com}-$ pared to those without claims.

Concerning differences in energy, nutrients and salt contents among product types, PC1 (35\%) and PC2 (29\%) accounted for $64 \%$ of total variability, as shown in Fig. 2(c). Energy, total fat and saturates had a great weight on PC1, while PC2 was positively loaded by carbohydrates and sugars and negatively loaded by protein amount (Fig. 2(d)).
Overall, the surveyed products showed high heterogeneity in their nutrition profiles and no clear groups were observed within the sweet snack category (Fig. 2(d)).

\section{Discussion}

To our knowledge, this is the first survey investigating the nutritional quality of a wide range of biscuits and sweet snacks sold on the Italian market.

Using the mandatory nutrition information on the package, biscuit and sweet snack categories were well grouped. This may be because each category is a combination of specific technological processes and ingredients used for their formulation. However, a high intra-category heterogeneity within both categories was observed, more pronounced for biscuits. A high variability in nutrition profile was also described by previous studies focusing on selected product categories (e.g. biscuits, snacks or yogurts) or on specific nutrients (e.g. salt, sugars or energy) ${ }^{(23-27)}$.

Comparing products with and without GF declarations, differences in nutrient contents emerged in both considered categories. These differences did not allow us to conclude whether GF products would have a better nutrition 
2816
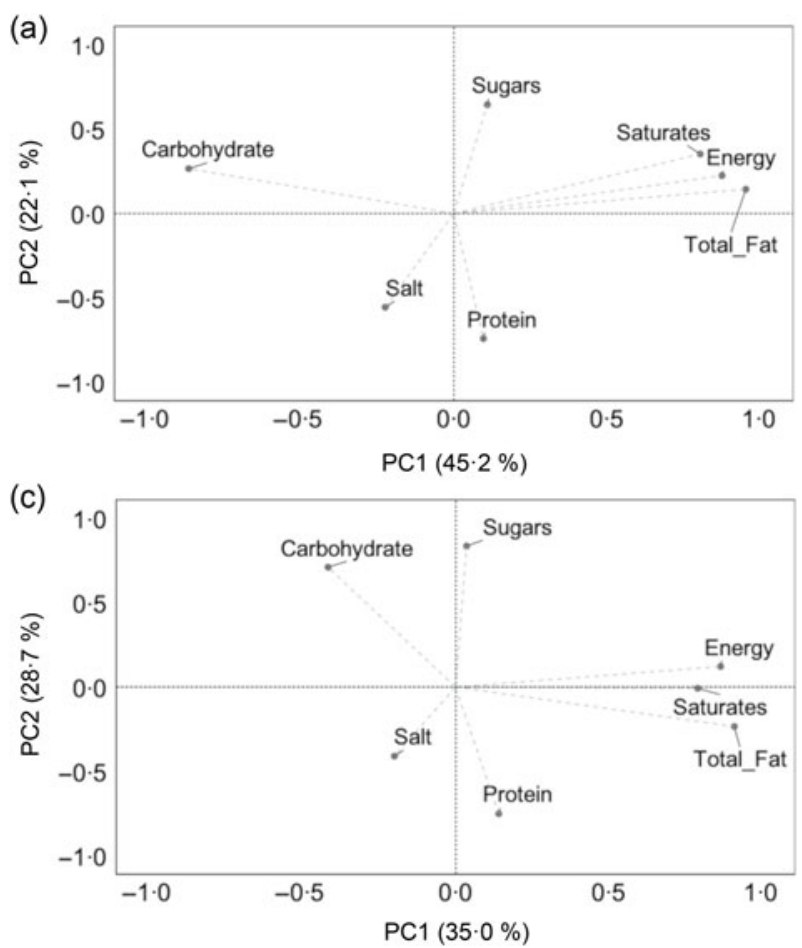

(b)

M Dall'Asta et al.

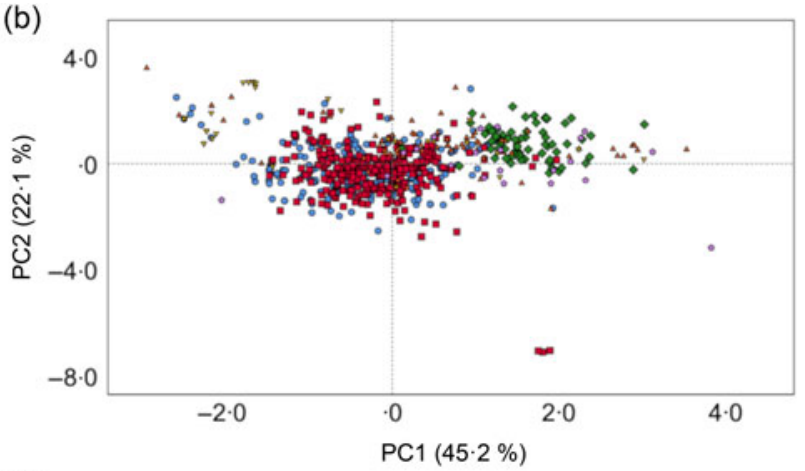

(d)

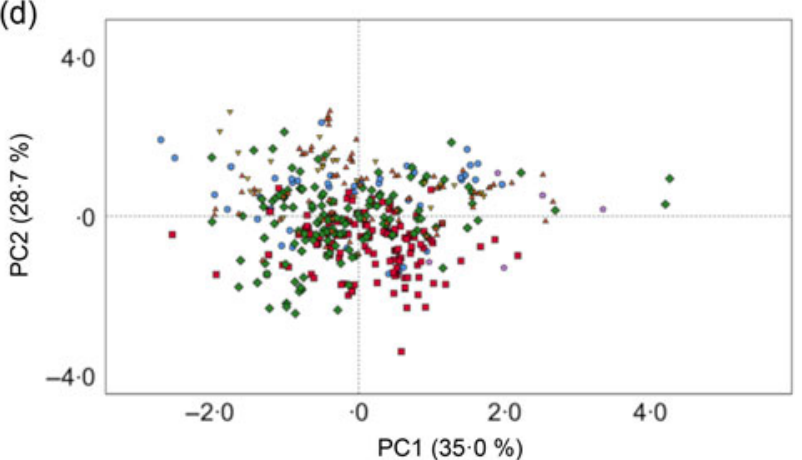

Fig. 2 (colour online) Principal component (PC) analysis describing the inter-product variability within each group of products based on their nutrient composition (energy $(\mathrm{kcal} / 100 \mathrm{~g})$, total fat $(\mathrm{g} / 100 \mathrm{~g})$, saturates $(\mathrm{g} / 100 \mathrm{~g})$, carbohydrate $(\mathrm{g} / 100 \mathrm{~g})$, sugars $(\mathrm{g} / 100 \mathrm{~g})$, protein $(\mathrm{g} / 100 \mathrm{~g})$ and salt $(\mathrm{g} / 100 \mathrm{~g})$ ). Loading plots of PC1 v. PC2 in biscuits (a) and sweet snacks (c); score plots of the nutrient composition of each product analysed within each category of products from PC1 and PC2 for biscuits (b) and sweet snacks (d). (b) O, tea cookies; $\square$, short-bread biscuits; $\diamond$, cream-filled wafer; $\triangle$, covered and/or sandwich cookies; $\nabla$, Italian traditional biscuits; $\triangle$, other biscuits. (d) ○, cream-filled sponge cake; $\square$, plain or cream/jam-filled croissant or pain au chocolat, $\diamond$, yogurt plumcake and muffin; $\Delta$, sponge cake; $\nabla$, cream/jam-filled shortbread cake; $\bullet$, cream-filled and/or covered chilled snack

profile than the CG counterparts. Our results are partially in line with previous studies evaluating the nutritional quality of GF bakery products currently present on Italian and other markets. Overall, these data suggest that, despite the consumers' perception of healthier attributes, GF products may not present a better nutrition profile than GC products $^{(12,13,16)}$.

After comparing products with and without nutrition claims, an overall, more favourable nutrition profile emerged for biscuits and sweet snacks carrying a claim. An exception was found for the higher salt content in both categories carrying a nutrition claim than the counterparts. Moreover, positive, despite limited, differences were observed between products with and without health claims, mostly in the biscuit category. Contrasting results have been previously reported on the role of NHC as a marker of the overall nutritional quality of food products. For instance, a wide range of NHC products sold in the United Kingdom, including cereal-based products, resulted in a slightly better nutrition profile (lower in total fat and saturates) than products not carrying $\mathrm{NHC}^{(15)}$. Conversely, a low relationship emerged between the front-of-pack labelling and the nutritional quality (determined by energy, sugar and sodium contents) in some products on the Mexican market ${ }^{(28)}$. Another study evaluating different food categories, such as cereal-derived items, sold in the Slovenian market supports the overall poor nutrient profiles of products carrying health claims ${ }^{(29)}$. Similarly, a report focusing on the US market also described that front-of-pack claims do not allow to distinguish 'healthy' food, although sometimes they may predict higher or lower levels of key nutrients ${ }^{(5)}$. Finally, other studies suggest that the consistency between health-related information on the pack and the real overall nutritional values of the product may be increased by implementing a nutrient profiling scheme ${ }^{(30,31)}$. Based on these findings, claims might be paradoxically misleading about the overall nutritional quality of foods, hindering the consumers' ability to select healthier foods ${ }^{(5,32)}$. Thus, all these studies highlight the need to pay attention to the overall nutrition profiles of NHC-carrying products, as well as on the way of presenting information in the front-of-pack. In this framework, it has been suggested that a simple and colour-coded front-of-pack can be an easy tool for discriminating the nutritional quality of foods for supporting consumers in making healthier food choices ${ }^{(33,34)}$.

In general, a major strength of this study is related to the wide number of products analysed. These products were selected from major Italian retailers and included the majority of biscuits and sweet snacks sold in Italy. However, a small number of items with specific declarations (e.g. health claims) was found during our online 
search. This may be due to a low penetration of specific information (e.g. NHC or GF), as previously described ${ }^{(35)}$. This could have generated a possible bias in the interpretation of results. Moreover, in this study we did not include either data from discounts that generally do not have online stores, or from other commercial channels (e.g. vending machines, cafés or pharmacies especially for GF products). Despite these limitations, to the best of our knowledge, this is the first study reporting on the nutritional quality of a broad range of sweet cereal-based products sold on the Italian market. Overall, focusing on the mandatory information, a high variability was described for the products analysed. This supports the importance of reading and understanding the label before selecting a product, rather than choosing a specific category of products and excluding others. No clear conclusion could be drawn regarding the quality of GF products as they presented contrasting results within the categories. Nutrition claims seem to be linked to a better quality of products, even though results highlighted the importance of reformulating them for reducing the salt content. No clear conclusion could be drawn for health claims due to the limited number of samples analysed.

Finally, considering the importance declarations may have on consumers' intention-to-buy, specific actions are needed by stakeholders, researchers and government representatives to improve the harmonisation and simplification of food labelling. Moreover, targeted nutrition education programmes for consumers can represent an essential tool for a better comprehension of the nutritional characteristics of products and food labelling.

\section{Conclusion}

The present study represents a thorough evaluation of the nutritional quality of prepacked biscuits and sweet cereal snacks sold on the Italian market, by taking into account different characteristics and regulated information on the pack. Thus, an analysis of the nutrition profiles of these categories based on the information reported on the package may be useful for implementing strategies for ameliorating the overall quality of the diet. Future studies are needed to further investigate the nutritional quality of food products present on the Italian market. These studies should include other cereal-based categories as well as other food groups. Consequently, these findings will elucidate if specific food characteristics or declarations might be used as markers of the overall quality of food products. This could support consumers in their purchasing process, without neglecting the importance of nutrition education programmes that are mandatory to improve consumers' food and nutrition literacy and consequently food choices.

\section{Acknowledgements}

Acknowledgements: The authors wish to thank all students who participated in the development of the dataset. Financial support: This research received no specific grant from any funding agency, commercial or not-forprofit sectors. Conflict of interest: None. Authorship: M.D., A.R. and D.A. were involved in protocol design, data analyses, interpretation of results and drafting of manuscript; N.P. participated in protocol design and critically reviewed the manuscript; D.M. designed the study protocol, performed data analyses, interpreted the results, critically reviewed the manuscript and had primary responsibility for the final content. All authors read and approved the final manuscript. Ethics of human subject participation: Ethical approval was not required.

\section{References}

1. European Union (2011) Regulation No 1169/2011 on the provision of food information to consumers. OJEU L304, 18-63.

2. European Union (2006) Regulation No 1924/2006 on nutrition and health claims made on foods. OJEU L404, 9-25.

3. Benson T, Lavelle F, Bucher T et al. (2018) The impact of nutrition and health claims on consumer perceptions and portion size selection: results from a nationally representative survey. Nutrients 10, 656.

4. van Trijp HCM \& van der Lans IA (2007) Consumer perceptions of nutrition and health claims. Appetite 48, 305-324.

5. Schaefer D, Hooker NH \& Stanton JL (2016) Are front of pack claims indicators of nutrition quality? Evidence from 2 product categories. J Food Sci 81, H223-234.

6. Kaur A, Scarborough P \& Rayner M (2017) A systematic review, and meta-analyses, of the impact of health-related claims on dietary choices. Int J Behav Nutr Phys Act 14, 93.

7. Roe B, Levy AS \& Derby BM (1999) The impact of health claims on consumer search and product evaluation outcomes: results from FDA experimental data. J Public Policy Mark 18, 89-105.

8. Calfee JE \& Pappalardo JK (1991) Public policy issues in health claims for foods. J Public Policy Mark 10, 33-53.

9. Harris JL, Thompson JM, Schwartz MB et al. (2011) Nutritionrelated claims on children's cereals: what do they mean to parents and do they influence willingness to buy? Public Health Nutr 14, 2207-2212.

10. van Buul VJ \& Brouns FJ (2015) Nutrition and health claims as marketing tools. Crit Rev Food Sci Nutr 55, 1552-1560.

11. European Union (2008) Regulation (EU) n. 828/2014 on the requirements for the provision of information to consumers on the absence or reduced presence of gluten in food. OJEU L228, 5-8.

12. Calvo-Lerma J, Crespo-Escobar P, Martínez-Barona S et al. (2019) Differences in the macronutrient and dietary fibre profile of gluten-free products as compared to their glutencontaining counterparts. Eur J Clin Nutr 73, 930-936.

13. Morreale F, Angelino D \& Pellegrini N (2018) Designing a score-based method for the evaluation of the nutritional quality of the gluten-free bakery products and their glutencontaining counterparts. Plant Foods Hum Nutr 73, 154-159.

14. Shangguan S, Afshin A, Shulkin M et al. (2019) A meta-analysis of food labeling effects on consumer diet behaviors and industry practices. Am J Prev Med 56, 300-314. 
15. Kaur A, Scarborough P, Matthews A et al. (2016) How many foods in the UK carry health and nutrition claims, and are they healthier than those that do not? Public Health Nutr 19, 988-997.

16. Cornicelli M, Saba M, Machello N et al. (2018) Nutritional composition of gluten-free food versus regular food sold in the Italian market. Dig Liver Dis 50, 1305-1308.

17. Leclercq C, Arcella D, Piccinelli R et al. (2009) The Italian National Food Consumption Survey INRAN-SCAI 2005-06: main results in terms of food consumption. Public Health Nutr 12, 2504-2532.

18. FAO (2018) Food Outlook-Biannual Report on Global Food Markets. Rome: FAO

19. Hieke S, Kuljanic N, Pravst I et al. (2016) Prevalence of nutrition and health-related claims on pre-packaged foods: a fivecountry study in Europe. Nutrients 8, 137.

20. Angelino D, Rosi A, Dall'Asta M et al. (2019) Evaluation of the nutritional quality of breakfast cereals sold on the Italian market: the Food Labelling of Italian Products (FLIP) study. Nutrients 11, 2827.

21. Dall'Asta M, Angelino D, Pellegrini N et al. (2020) The nutritional quality of organic and conventional food products sold in Italy: results from the Food Labelling of Italian Products (FLIP) study. Nutrients 12, 1273.

22. Angelino D, Rosi A, Vici G et al. (2020) Nutritional quality of plant-based drinks sold in Italy: the Food Labelling of Italian Products (FLIP) study. Foods 9, 682.

23. Goglia R, Spiteri M, Menard C et al. (2010) Nutritional quality and labelling of ready-to-eat breakfast cereals: the contribution of the French observatory of food quality. EurJ Clin Nutr 64, Suppl. 3, S20-S25.

24. Hashem KM, He FJ, Alderton SA et al. (2018) Cross-sectional survey of the amount of sugar and energy in cakes and biscuits on sale in the UK for the evaluation of the sugarreduction programme. BMJ Open $\mathbf{8}$, e019075.

25. Lalor F, Kennedy J, Flynn MA et al. (2010) A study of nutrition and health claims - a snapshot of what's on the Irish market. Public Health Nutr 13, 704-711.
26. Moore JB, Horti A \& Fielding BA (2018) Evaluation of the nutrient content of yogurts: a comprehensive survey of yogurt products in the major UK supermarkets. BMJ Open 8, $\mathrm{e} 021387$.

27. Pombo-Rodrigues S, Hashem KM, He FJ et al. (2017) Salt and sugars content of breakfast cereals in the UK from 1992 to 2015. Public Health Nutr 20, 1500-1512.

28. Nieto C, Rincon-Gallardo Patino S, Tolentino-Mayo L et al. (2017) Characterization of breakfast cereals available in the Mexican market: sodium and sugar content. Nutrients 16,9.

29. Pivk Kupirovic U, Miklavec K, Hribar M et al. (2019) Nutrient profiling is needed to improve the nutritional quality of the foods labelled with health-related claims. Nutrients $29,11$.

30. Hughes C, Wellard L, Lin J et al. (2013) Regulating health claims on food labels using nutrient profiling: what will the proposed standard mean in the Australian supermarket? Public Health Nutr 16, 2154-2161.

31. Maschkowski G, Hartmann M \& Hoffmann J (2014) Healthrelated on-pack communication and nutritional value of ready-to-eat breakfast cereals evaluated against five nutrient profiling schemes. BMC Public Health 14, 1178.

32. Taillie LS, Ng SW, Xue Y et al. (2017) No fat, no sugar, no salt ... no problem? Prevalence of "low-content" nutrient claims and their associations with the nutritional profile of food and beverage purchases in the United States. J Acad Nutr Diet 117, 1366-1374 e6.

33. Cecchini M \& Warin L (2016) Impact of food labelling systems on food choices and eating behaviours: a systematic review and meta-analysis of randomized studies. Obes Rev 17, 201-210.

34. Emrich TE, Qi Y, Lou WY et al. (2017) Traffic-light labels could reduce population intakes of calories, total fat, saturated fat, and sodium. PLOS ONE 12, e0171188.

35. Storcksdieck genannt Bonsmann S, Celemín LF, Larrañaga A et al. (2010) Penetration of nutrition information on food labels across the EU-27 plus Turkey. Eur J Clin Nutr 64, 1379-1385. 